\title{
Endosonography-guided gallbladder drainage in a patient with intestinal malrotation
}
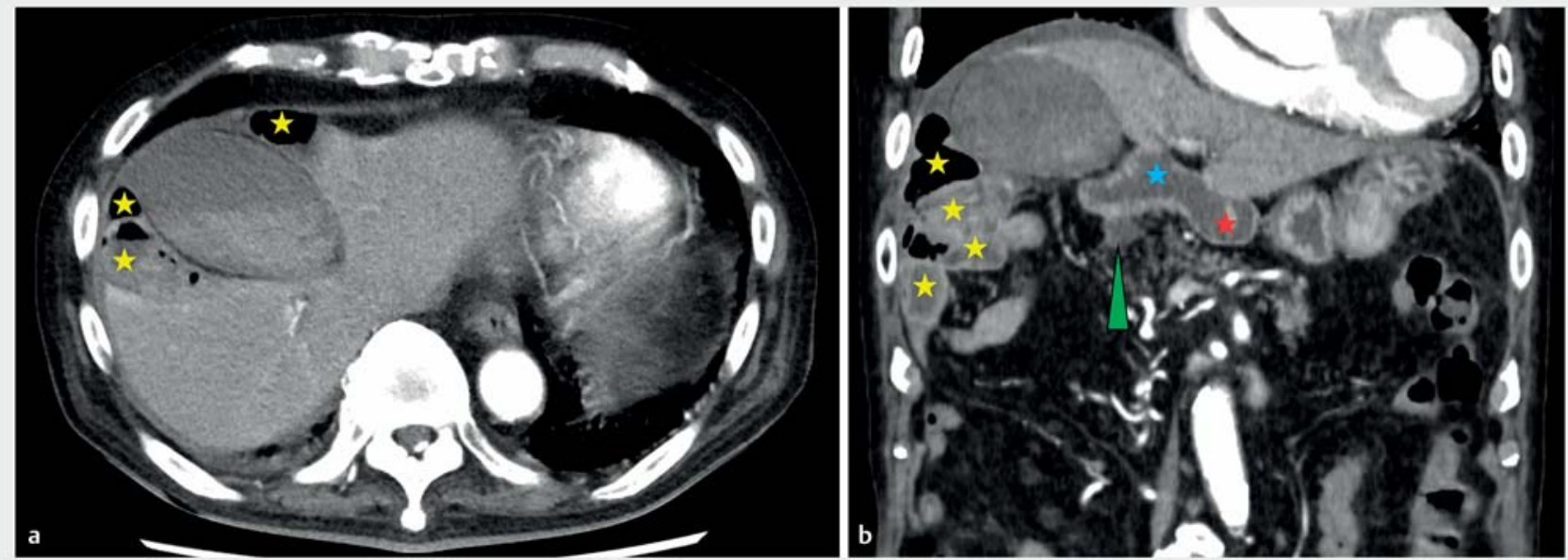

- Fig. 1 Computed tomography with contrast. a Axial view revealing a severely inflamed gallbladder, intestinal malrotation with the Chilaiditi sign caused by distal duodenum or proximal jejunum (yellow stars). b Coronal view showing intestinal malrotation with the first part (red star) and second part (blue star) of the duodenum, common bile duct (green arrowhead), and distal duodenum or proximal jejunum (yellow stars).

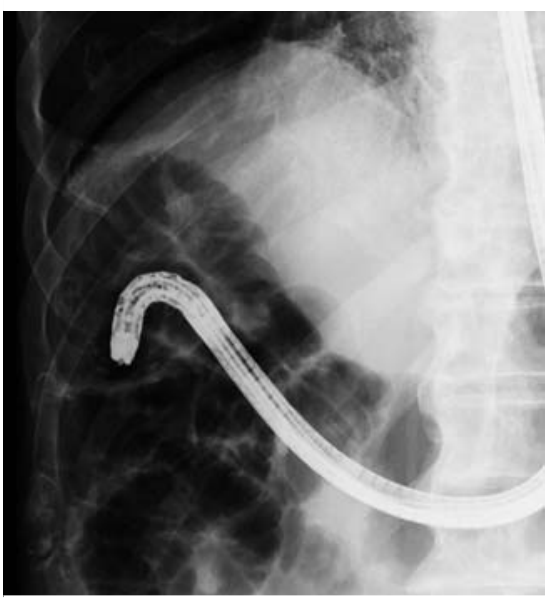

- Fig. 2 Forward-viewing endoscope advanced deep into the third part of the malrotated duodenum under fluoroscopic guidance.

Endosonography-guided gallbladder drainage (EUS-GBD) is increasingly performed in cholecystitis patients who are not candidates for surgery, with similar success rates and fewer adverse events compared to percutaneous drainage, and with good long-term outcomes [13]. EUS-GBD is also preferred over endo-
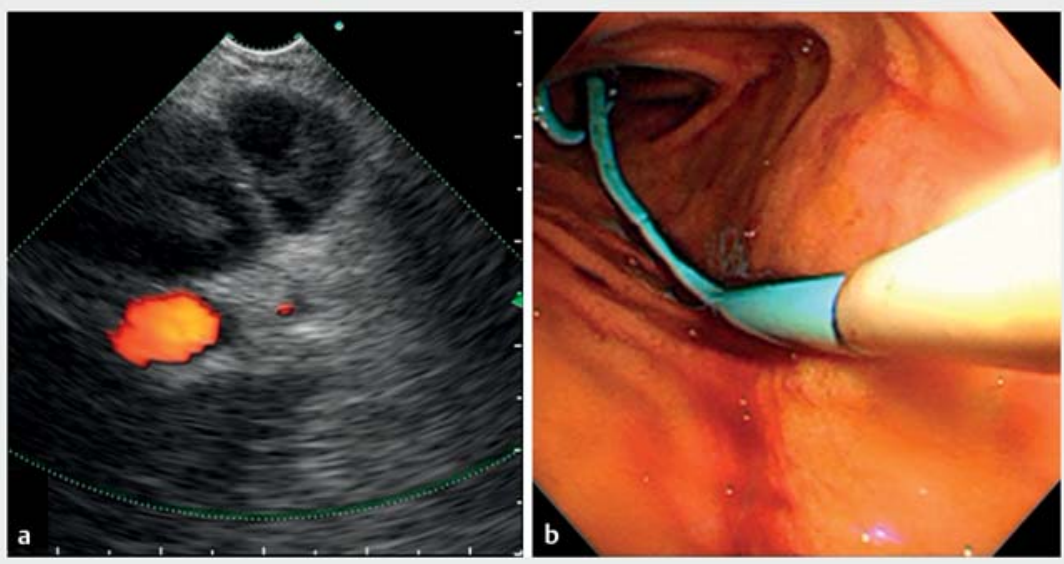

Fig. 3 a The neck of the gallbladder visualized with a forward-viewing endosonoscope. b Two 6-cm, 7-Fr pigtail plastic stents were placed for gallbladder drainage.

scopic transpapillary naso-gallbladder drainage (ET-GBD) as it is associated with higher success rates and lower rates of recurrent cholecystitis [4].

An 88-year-old bedridden man with a history of rheumatoid arthritis and cerebral infarction was admitted for treatment of interstitial pneumonia. After 2 months in hospital, he was referred to the gastroenterology department because of severe right upper quadrant pain. Contrast computed tomography (CT) revealed a severely inflamed gallbladder, intestinal malrotation, moderate ascites, and the Chilaiditi sign ( $\mathbf{F i g} \mathbf{1}$ ). The patient was judged to be unfit to undergo surgery. 


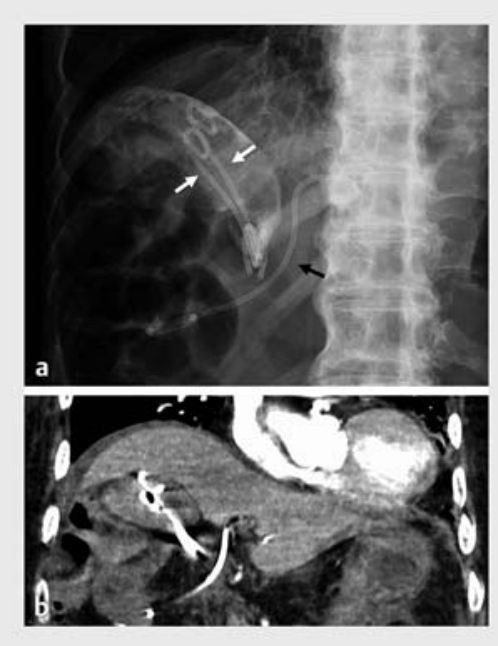

- Fig. 4 Follow-up. a Postprocedural abdominal radiograph showing two plastic stents placed in the gallbladder (white arrows) and one stent placed in the bile duct during preceding endoscopic retrograde cholangiopancreatography (black arrow). b No bile leakage or free intraperitoneal air was observed on computed tomography (coronal view).

Percutaneous gallbladder drainage was not possible due to ascites and the presence of bowel between the diaphragm and the liver. As the patient was taking clopidogrel, ET-GBD was planned.

Esophagogastroduodenoscopy was performed under fluoroscopic guidance and confirmed intestinal malrotation ( Fig.2). While bile duct cannulation was, with some difficulty, achieved during endoscopic retrograde cholangiopancreatography, the guidewire could not be advanced into the gallbladder. EUS-GBD was therefore performed after temporary discontinuation of the clopidogrel therapy.

A forward-viewing endosonoscope (TGFUC260]; Olympus Corp., Tokyo, Japan) was used for the EUS-GBD due to the intestinal malrotation. A 19-gauge needle was used to puncture the neck of the gallbladder and a guidewire was advanced. After mechanical dilation, a second guidewire was placed and two plastic stents were successfully placed in the gallbladder ( $\triangleright$ Fig. 3 , $\triangleright$ Video 1 ). The patient's symptoms and inflammatory markers both improved rapidly after the procedure. Follow-up CT showed no air or bile leakage ( $>$ Fig. 4 ).

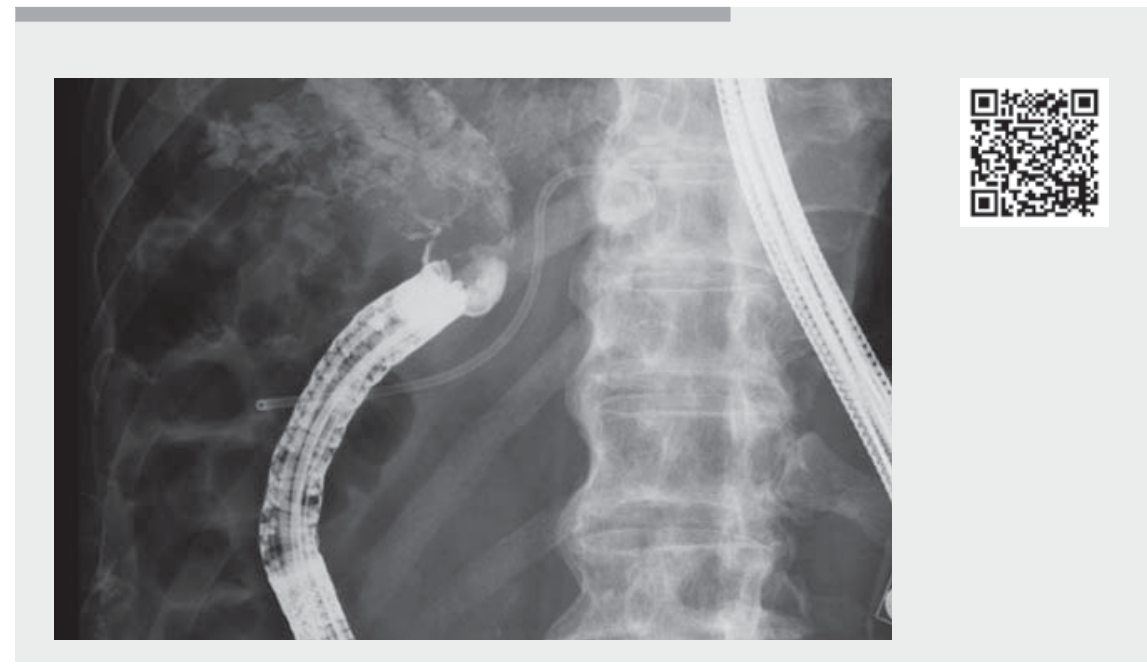

$\checkmark$ Video 1 Esophagogastroduodenoscopy of malrotated duodenum under fluoroscopic guidance, endoscopic retrograde cholangiopancreatography, and endosonography-guided gallbladder drainage using a forward-viewing endosonoscope due to intestinal malrotation.

EUS-GBD is an attractive option in patients with intestinal malrotation, as ET-GBD is particularly difficult in this population. Use of a forward-viewing endosonoscope was beneficial for selecting the puncture point and deploying plastic stents in this patient.

Endoscopy_UCTN_Code_TTT_1AS_2AD

\section{Competing interests}

The authors declare that they have no conflict of interest.

The authors

\section{Takeshi Okamoto ${ }^{1}$, Kenji Nakamura ${ }^{1,2} \odot$}

1 Department of Gastroenterology, St. Luke's International Hospital, Tokyo, Japan

2 Department of Gastroenterology, Tokyo Dental College, Ichikawa General Hospital, Chiba, Japan

\section{Corresponding author}

\section{Takeshi Okamoto, MD}

Department of Gastroenterology, St. Luke's International Hospital, 9-1 Akashicho, Chuo-ku, Tokyo 104-8560, Japan okamotot@luke.ac.jp
References

[1] Luk SW, Irani S, Krishnamoorthi R et al. Endoscopic ultrasound-guided gallbladder drainage versus percutaneous cholecystostomy for high risk surgical patients with acute cholecystitis: a systematic review and meta-analysis. Endoscopy 2019; 51: 722732

[2] Teoh AYB, Kitano M, Itoi T et al. Endosonography-guided gallbladder drainage versus percutaneous cholecystostomy in very highrisk surgical patients with acute cholecystitis: an international randomised multicentre controlled superiority trial (DRAC 1). Gut 2020; 69: 1085-1091

[3] Choi JH, Lee SS, Choi JH et al. Long-term outcomes after endoscopic ultrasonography-guided gallbladder drainage for acute cholecystitis. Endoscopy 2014; 46: 656-661

[4] Krishnamoorthi R, Jayaraj M, Thoguluva Chandrasekar $V$ et al. EUS-guided versus endoscopic transpapillary gallbladder drainage in high-risk surgical patients with acute cholecystitis: a systematic review and metaanalysis. Surg Endosc 2020; 34: 1904-1913

\section{Bibliography}

Endoscopy 2022; 54: E180-E181

DOI 10.1055/a-1463-2085

ISSN 0013-726X

published online 28.4.2021

(c) 2021. Thieme. All rights reserved.

Georg Thieme Verlag KG, Rüdigerstraße 14,

70469 Stuttgart, Germany 